\title{
Biomechanical analysis on custom-made insoles in gait of idiopathic pes cavus
}

\author{
Jungkyu Choi ${ }^{1}$, Ji Yong Jung ${ }^{1}$, Yonggwan Won ${ }^{2}$, Jung-Ja Kim ${ }^{3,4^{*}}$ \\ From 4th Congress of the International Foot and Ankle Biomechanics (i-FAB) Community \\ Busan, Korea. 8-11 April 2014
}

The purpose of this study was to evaluate the effects of custom-made insoles based on the foot pressures and electromyography (EMG) activities in a subject group of idiopathic pes cavus which the term used to describe a foot type with an excessively high medial longitudinal arch [1-3]. The study was conducted using on 10 persons who were diagnosed idiopathic pes cavus by a podiatrist (an age $22.3 \pm 0.08$ years, a height $159.9 \pm 2.2 \mathrm{~cm}$, a weight $50.8 \pm 3.69 \mathrm{~kg}$, a foot size $237.9 \pm 3.27 \mathrm{~mm}$, mean \pm SD) All subjects had no history of injury in the musculoskeletal system of the lower extremities except pes cavus. The subjects walked on a treadmill under two different experimental conditions: walking with Normal Shoes (NS) and walking with normal shoes equipped with custom-made insoles (CI) molded with the aim of reducing supination of pes cavus (Figure 1). When walking, plantar foot pressure data such as the maximum force (MF), the contacting area (CA), the peak pressure (PP) and the mean pressure (MP) were collected using Pedar-X System (Novel Gmbh, Germany) and EMG activity of lower limb muscles such as Rectus Femoris (RF), Tibialis Anterior (TA), Musculus Biceps Femoris (MBF) and Medial Gastrocnemius (MG) were also gathered using Delsys EMG Work System (Delsys, USA) [4-6]. Accumulated data was then analyzed using paired $t$-test in order to investigate the effects of each of experimental condition. As a result of the analysis, MF, PP and MP of midfoot were increased by increased CA of midfoot on CI condition, so CA and MF of forefoot and rearfoot were decreased. In addition, PP and MP of rearfoot were decreased significantly. As a result of the analysis in the view point of stance phase, MF, PP and MP in the initial contact and the loading response were decreased significantly on CI condition. In the mid stance, MF, PP and

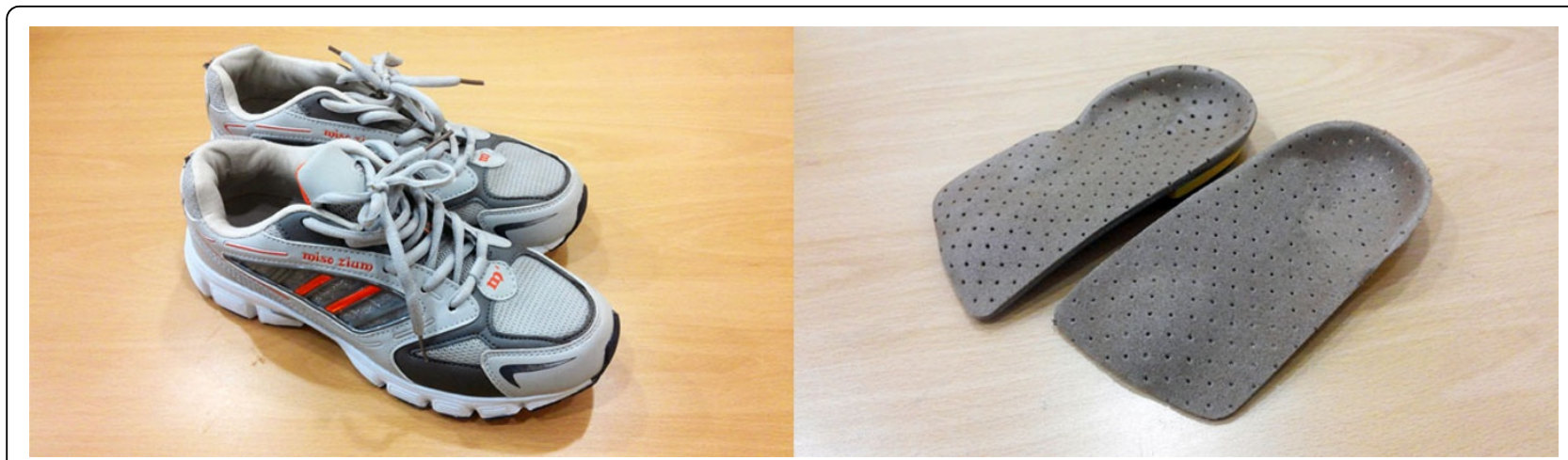

Figure 1 Normal Shoes (NS) and Custom-made Insoles (Cl)

\footnotetext{
* Correspondence: jungjakim@jbnu.ac.kr

${ }^{3}$ Division of Biomedical Engineering, Chonbuk National University, Jeonju, Jeolabuk-do, 561-756, Korea

Full list of author information is available at the end of the article
} 
Table 1 The results of plantar pressure in stance phase.

\begin{tabular}{|c|c|c|c|c|c|}
\hline & & \multicolumn{2}{|c|}{ Normal shoes (NS) } & \multicolumn{2}{|c|}{ Custom-made Insoles (Cl) } \\
\hline & & mean & SD & mean & SD \\
\hline \multirow[t]{4}{*}{ Contacting area $\left(\mathrm{cm}^{2}\right)$} & Initial contact & 15.82 & 9.94 & 17.43 & 10.78 \\
\hline & Loading response & 42.25 & 17.92 & 40.97 & 13.7 \\
\hline & Mid stance & 74.18 & 4.21 & 74.9 & 5.79 \\
\hline & Terminal stance & 47.17 & 14.32 & $57.03^{*}$ & 15.25 \\
\hline \multirow[t]{4}{*}{ Maximum force $(\mathrm{N})$} & Initial contact & 55.65 & 44.15 & 53.66 & 44.65 \\
\hline & Loading response & 254.15 & 125.91 & $243.16^{*}$ & 120.7 \\
\hline & Mid stance & 400.55 & 11.06 & $425.76^{*}$ & 38.87 \\
\hline & Terminal stance & 283.42 & 128.78 & $335.14^{*}$ & 156.3 \\
\hline \multirow[t]{4}{*}{ Peak pressure $(\mathrm{kPa})$} & Initial contact & 41.5 & 28.26 & $36.75^{*}$ & 28.71 \\
\hline & Loading response & 115.07 & 41.63 & $112.14^{*}$ & 36.38 \\
\hline & Mid stance & 127.05 & 17.04 & $139.61^{*}$ & 19.58 \\
\hline & Terminal stance & 128.97 & 45.55 & $143.57^{*}$ & 41.37 \\
\hline \multirow[t]{4}{*}{ Mean pressure (kPa) } & Initial contact & 25.51 & 16.58 & $22.75^{*}$ & 13.69 \\
\hline & Loading response & 55.42 & 16.72 & 54.27 & 16.15 \\
\hline & Mid stance & 54.84 & 4.83 & $57.71^{*}$ & 5.01 \\
\hline & Terminal stance & 56.45 & 15.02 & $54.83^{*}$ & 15.24 \\
\hline
\end{tabular}

${ }^{*} \mathrm{p}<0.05$ significant difference between NS and $\mathrm{Cl}$

MP were increased significantly by the increased CA of midfoot on $\mathrm{CI}$ condition. MF and PP were also increased significantly in the terminal stance but MP was decreased (Table 1). In case of EMG, all the muscle activities were decreased significantly on CI condition. An important contribution of this study is an analysis of all the changes in a muscle activities caused by wearing the custom-made insoles. Thus, the result of this study can be applied for designing functional insoles and lower extremity orthoses for individuals with pes cavus.

\section{Trial registration}

Current Controlled Trials ISCRTN73824458

\begin{abstract}
Authors' details
'Department of Healthcare Engineering, Chonbuk National University, Jeonju, Jeolabuk-do, 561-756, Korea. ${ }^{2}$ School of Electronics and Computer Engineering, Chonnam National University, Gwangju, 500-757, Korea. ${ }^{3}$ Division of Biomedical Engineering, Chonbuk National University, Jeonju, Jeolabuk-do, 561-756, Korea. ${ }^{4}$ Research Center of Healthcare \& Welfare Instrument for the Aged, Chonbuk National University, Jeonju, Jeolabuk-do, 561-756, Korea.
\end{abstract}

\section{Published: 8 April 2014}

\section{References}

1. Burns J, Crosbie J, Hunt A, Ouvrier R: The effect of pes cavus on foot pain and plantar pressure. Clinical Biomechanics 2005, 20:877-882.

2. Kim J, Lee S, Lee H: First metatarsal dorsal close wedge osteotomy combined with medial cuneiform plantar open wedge osteotomy for the treatment of a cavus Foot. The Korean Orthopaedic Association 2010, 45:32-38.

3. Sabir M, Lyttle D: Pathogenesis of pes cavus in Charcot-Marie-Tooth disease. Clin Orthop Relat Res 1983, 175:173-178.
4. Kim E, Cho H, Jung T, Kim S, Jung J: The biomechanical evaluation of functional insoles. Korean Journal of Sport Biomechanics 2010, 20:345-353.

5. Jung S, Yoo J, Kim K, Song C, Jo B, Jang I, Kim J, Lee S: Ankle Foot Complex. In Perry's Gait Analysis. 1 edition. Seoul: Yeong Mun Publishing Company;Park B 2006:57-62.

6. Park S, Lee S, Kang H, Kim S: EMG analysis of Lower Limb Muscle Activation Pattern During Pedaling: Experiments and Computer Simulations. International Journal of Precision Engineering and Manufacturing 2012, 13:601-608.

doi:10.1186/1757-1146-7-S1-A131

Cite this article as: Choi et al:: Biomechanical analysis on custom-made insoles in gait of idiopathic pes cavus. Journal of Foot and Ankle Research 2014 7(Suppl 1):A131.

\section{Submit your next manuscript to BioMed Central and take full advantage of:}

- Convenient online submission

- Thorough peer review

- No space constraints or color figure charges

- Immediate publication on acceptance

- Inclusion in PubMed, CAS, Scopus and Google Scholar

- Research which is freely available for redistribution 